\title{
Clinical characteristics of children with chronic rheumatic valvular heart disease in Cardiology Unit, Assiut University Children Hospital
}

\author{
Lamiaa E. Ali", Farouk E. Hassanein, Faisal Alkhateeb A. Abdullah \\ Pediatrics Department, Faculty of Medicine, Assiut University, Assiut, Egypt \\ *Corresponding author: Lamiaa E. Ali, E-mail: mohamedhafez2008@ yahoo.com
}

\begin{abstract}
Background: chronic rheumatic heart disease (RHD) is still common in developing countries and associated with major complications and high mortality. Aim: to describe clinical characteristics of children with chronic rheumatic valvular heart disease. Patients and Methods: the study included fifty patients with chronic rheumatic valvular heart disease attending Assiut University Children Hospital over six months. Full through history and clinical examinations were done to all cases. All cases have been subjected to chest X-ray, standard 12-lead ECG, and echocardiography. Results: female patients were slightly commoner than male patients. Mitral valve was the commonest valve affected followed by aortic valve. Regarding ECG, left atrial hypertrophy was the commonest finding and mitral regurge was the commonest valve lesion. While, left atrial hypertrophy was the commonest finding in chest X-ray. Respecting echocardiography, there was slightly increased in left ventricular end diastolic diameter and left atrium. Heart failure was the most common complication that occurs in RHD patients. Patients' compliant with long acting penicillin (LAP) were more than non-compliant. Conclusion: echocardiography is the most important tool for evaluation of valvular heart disease. Left atrial hypertrophy is the commonest finding by ECG. There is increase in left ventricular end diastolic diameter and left atrium by echocardiography. Left atrial hypertrophy is the commonest finding in chest X-ray. Mitral valve is the commonest valve affected followed by aortic valve. Patients' compliant with LAP are more than non-compliant patients. Recommendation: echocardiography must be used as a screening tool for early detection of subtle cases of RHD. Application of control programs with special emphasis on the regular use of secondary prophylaxis.
\end{abstract}

Keywords: Rheumatic heart disease, Rheumatic fever, Long acting penicillin, secondary prevention.

\section{Introduction}

Chronic rheumatic heart disease (RHD)

is characterized by recurrent inflammation with fibrinous repair. The main anatomic changes of the valve include leaflet thickening, commissural adhesion, and shortening of tendinious cords. It is caused by an autoimmune reaction to group $\mathrm{A} \beta$-hemolytic streptococci that lead to valvular damage ${ }^{(\mathbf{1})}$.

Recurrent attacks of rheumatic fever (RF) lead to valvular heart disease, heart complications are long-term and severe, if valves are involved. Recurrence of $\mathrm{RF}$ is common in absence of maintenance of low dose of antibiotics, especially during first few years after first episode ${ }^{(2)}$.

About $80-90 \%$ of children younger than fifteen years live in areas where RHD is endemic. Mitral incompetence (MI) is the commonest lesion found in patients with chronic $\mathrm{RHD}^{(3)}$.

Received: 23/10/2018

Accepted: 19/11/2018
It is very important to distinguish pathological mitral incompetence from physiological incompetence. Pulmonary stenosis is rarely found in patients with chronic rheumatic heart disease, usually present at birth. Echocardiography was shown to be more effective in detecting carditis than clinical examination ${ }^{(4)}$.

Where facilities for echocardiography are available, regular follow up (at least once per year) should be undertaken. If echocardiography is not available; diagnosis of valvular disease must depend on careful clinical examination supported by an electrocardiogram (ECG) and chest X-ray ${ }^{(5)}$.

The necessity of surgery for chronic rheumatic valve disease is determined by the severity of the patient's symptoms and/or evidence that cardiac function is significantly impaired $^{(6)}$. 
As regard treatment of infective endocarditis, several weeks are needed for a vegetation to organize completely, so that treatment must be continued through this period $^{(7)}$.

\section{Aim of the study:}

To describe clinical characteristics of children with chronic rheumatic valvular heart disease as regard demography, electrocardiogram, chest X-ray, echocardiography, degree of valvular affection, and compliance with long acting penicillin(LAP).

\section{Patients and Methods}

Study design: This is a descriptive study.The study was conducted in Cardiology unit at Assiut University Children Hospital in the period from the $1^{\text {st }}$ of September 2016 to the end of February 2017.

Population of the study: Fifty children aged from 3 years to 17 years with chronic rheumatic valvular heart disease.

Inclusion criteria: In-patients, out-patients at Cardiology department, newly diagnosed cases come with activity or with complications.

Exclusion criteria: All cases with acquired cardiac disease other than rheumatic cause, congenital heart disease, patients with neurological problems other than rheumatic chorea.

Ethical statement: The study protocol was approved by the Ethical Committee of Assiut Faculty of Medicine. Any data taken from the patient was dealt with confidential manner. Informed consents were taken from parents' or guardians' of the participated children.

\section{Data collection:}

All patients were subjected to full history taking (e.g. age, sex, and prophylaxis with long acting penicillin) and clinical examination (e.g. height, weight, body mass index, body surface area, general examination, and complete cardiac and chest examination).

All cases were subjected to the following investigations: Chest X-ray (posteroanterior view), Standard 12-lead ECG, and Echocardiography.

Statistical analysis: Data were analyzed using the statistical package for social sciences (SPSS
Inc., Chicago, Illinois, USA) version 20.0. Quantitative data were expressed as mean \pm standard deviation (SD). Qualitative data were expressed as frequency and percentage.

\section{Results}

The study includes 50 cases of chronic RHD. They attended at Assiut University Children Hospital. The study was conducted on children from 3 years old to 18 years of age; the majority of them were in age range 10-15 years. They were 21 males and 29 females.

Table (1): Demographic and clinical characteristics of the study patient's group

\begin{tabular}{|c|c|}
\hline Characteristic & $\mathbf{N}=\mathbf{5 0}(\%)$ \\
\hline Age $($ mean \pm SD years $)$ & $12.5 \pm 2.5$ \\
\hline Males & $21(42 \%)$ \\
\hline Females & $29(58 \%)$ \\
\hline Weight (mean \pm SD kg) & $39.53 \pm 13.89$ \\
\hline Height (mean \pm SD meter) & $137.36 \pm 17.9$ \\
\hline Body mass index $($ mean \pm SDk g/m²) & $20.06 \pm 3.68$ \\
\hline Body surface area $\left(\right.$ mean $\left.\pm \mathrm{SDm}^{2}\right)$ & $1.22 \pm 0.29$ \\
\hline $\begin{array}{l}\text { Systolic blood pressure (mean } \pm \text { SD } \\
\text { mmHg) }\end{array}$ & $106.2 \pm 10.28$ \\
\hline $\begin{array}{l}\text { Diastolic blood pressure (mean } \pm \text { SD } \\
\text { mmHg) }\end{array}$ & $69.1 \pm 8.73$ \\
\hline
\end{tabular}
characteristics of the study are within normal range.

Table (2): ECG findings in patient with chronic rheumatic valvular heart disease

\begin{tabular}{|l|cc|ll|}
\hline \multicolumn{1}{|c|}{ Finding } & $\mathbf{5 0}$ & & $\%$ \\
\hline Normal ECG & 12 & 4.0 & 2 \\
\hline Prolonged PR interval & 5 & 0.0 & 1 \\
\hline Rt atrial hypertrophy & 2 & 0 & 4. \\
\hline Lt atrial hypertrophy & 19 & 8.0 & 3 \\
\hline $\begin{array}{l}\text { Rt ventricular } \\
\text { hypertrophy }\end{array}$ & 3 & 0 & 6. \\
\hline Lt ventricular hypertrophy & 10 & 0 & 2 \\
\hline Biventricular hypertrophy & 3 & 0 & 6. \\
\hline Abnormal rhythm & 1 & 0 & 2. \\
\hline
\end{tabular}

Table (2) shows ECG finding of our study group. About one fourth (24\%) of the 
patients have normal ECG. While, left atrial hypertrophy is the commonest finding in ECG.

Table (3): Echocardiographic parameters in patient with chronic rheumatic valvular heart disease

\begin{tabular}{|l|c|}
\hline \multicolumn{1}{|c|}{ Parameters } & Mean \pm SD \\
\hline Pulmonary artery (PA, mm) & $13.63 \pm 5.1$ \\
\hline Left atrium (LA, mm) & $19.2 \pm 9.3$ \\
\hline Aortic root (AO, mm) & $15.81 \pm 5.7$ \\
\hline $\begin{array}{l}\text { Right ventricular anterior wall (RVAW, } \\
\text { mm) }\end{array}$ & $4.98 \pm 1.5$ \\
\hline Right ventricle (RV, mm) & $11.59 \pm 2.2$ \\
\hline $\begin{array}{l}\text { Interventricular septum during systole } \\
\text { (IVSS, mm) }\end{array}$ & $6.99 \pm 3$ \\
\hline $\begin{array}{l}\text { Left ventricular end diastolic diameter } \\
\text { (LVEDD, mm) }\end{array}$ & $31.67 \pm 17.7$ \\
\hline $\begin{array}{l}\text { Left ventricular end systolic diameter } \\
\text { (LVESD, mm) }\end{array}$ & $23.1 \pm 13.6$ \\
\hline $\begin{array}{l}\text { Left ventricular posterior wall during } \\
\text { systole (LVPWS, mm) }\end{array}$ & $7.78 \pm 4.3$ \\
\hline Fraction shortening (FS, \%) & $36.9 \pm 9.7$ \\
\hline \begin{tabular}{l} 
Ejection fraction (EF, \%) \\
\hline
\end{tabular} & $69.82 \pm 12.6$ \\
\hline
\end{tabular}

Table (3) shows mean \pm SD for each Echocardiographic parameter as regard our cases in the study group. There is slightly increase in LVEDD and LA. Ejection fraction and fraction shortening are within normal range.

Table (4): Chest X-ray findings in chronic rheumatic valvular heart disease

\begin{tabular}{|l|rr|rr|}
\hline \multicolumn{1}{|c|}{ Finding } & O. & & \\
\hline Increase cardiothoracic ratio & & 6 & 2.0 & 1 \\
\hline Normal X-ray & 2 & 1 & 4.0 & 2 \\
\hline Rt atrial hypertrophy & & 2 & .0 & 4 \\
\hline Left atrial hypertrophy & & 1 & & 3 \\
\hline Right ventricular enlargement & & 3 & & 6 \\
\hline Left ventricular enlargement & & 1 & 0 & \\
\hline Bi ventricular enlargement & & 3 & .0 & 6 \\
\hline
\end{tabular}

Table (4) shows X-ray findings of our study group. Left atrial hypertrophy is the commonest (38\%) finding in chest X-ray.

Table (5): A-Different degrees of valve lesions of the study sample

\begin{tabular}{|l|c|c|c|c|c|c|}
\hline \multirow{2}{*}{\multicolumn{1}{c|}{ Valve lesion }} & \multicolumn{2}{c|}{ Mild } & \multicolumn{2}{c|}{ Moderate } & \multicolumn{2}{c|}{ severe } \\
\cline { 2 - 7 } & NO. & \% & NO. & \% & NO. & \% \\
\hline Mitral regurge (MR) & 11 & $22 . .0$ & 4 & 8.0 & 1 & 2.0 \\
\hline Mitral stenosis (MS) & 8 & 16.0 & 2 & 4.0 & 1 & 2.0 \\
\hline Aortic regurge (AR) & 4 & 8.0 & 0 & 0.0 & 0 & 0.0 \\
\hline Aortic stenosis (AS) & 8 & 16.0 & 0 & 0.0 & 0 & 0.0 \\
\hline Tricuspid regurge (TR) & 1 & 2.0 & 0 & 0.0 & 0 & 0.0 \\
\hline Tricuspid stenosis (TS) & 0 & 0.0 & 0 & 0.0 & 0 & 0.0 \\
\hline Pulmonary regurge (PR) & 1 & 2.0 & 0 & 0.0 & 0 & 0.0 \\
\hline Pulmonary stenosis (PS) & 1 & 2.0 & 0 & 0.0 & 0 & 0.0 \\
\hline
\end{tabular}

Table (5): B- Multivalvular lesions

\begin{tabular}{|c|c|c|}
\hline \multicolumn{1}{|c|}{ Characteristic } & \multirow{2}{*}{ NO. } & \multirow{2}{*}{$\%$} \\
\cline { 1 - 2 } Multi valvular lesions & 2 & 4.0 \\
\hline MR+AR & 3 & 6.0 \\
\hline AS+AR & 1 & 2.0 \\
\hline PR+TR & 1 & 2.0 \\
\hline TS+MR & 2 & 4.0 \\
\hline
\end{tabular}

Table (5) shows the numbers and percentages for severity of valvular lesions. Mitral valve is the commonest valve affected followed by aortic valve. 


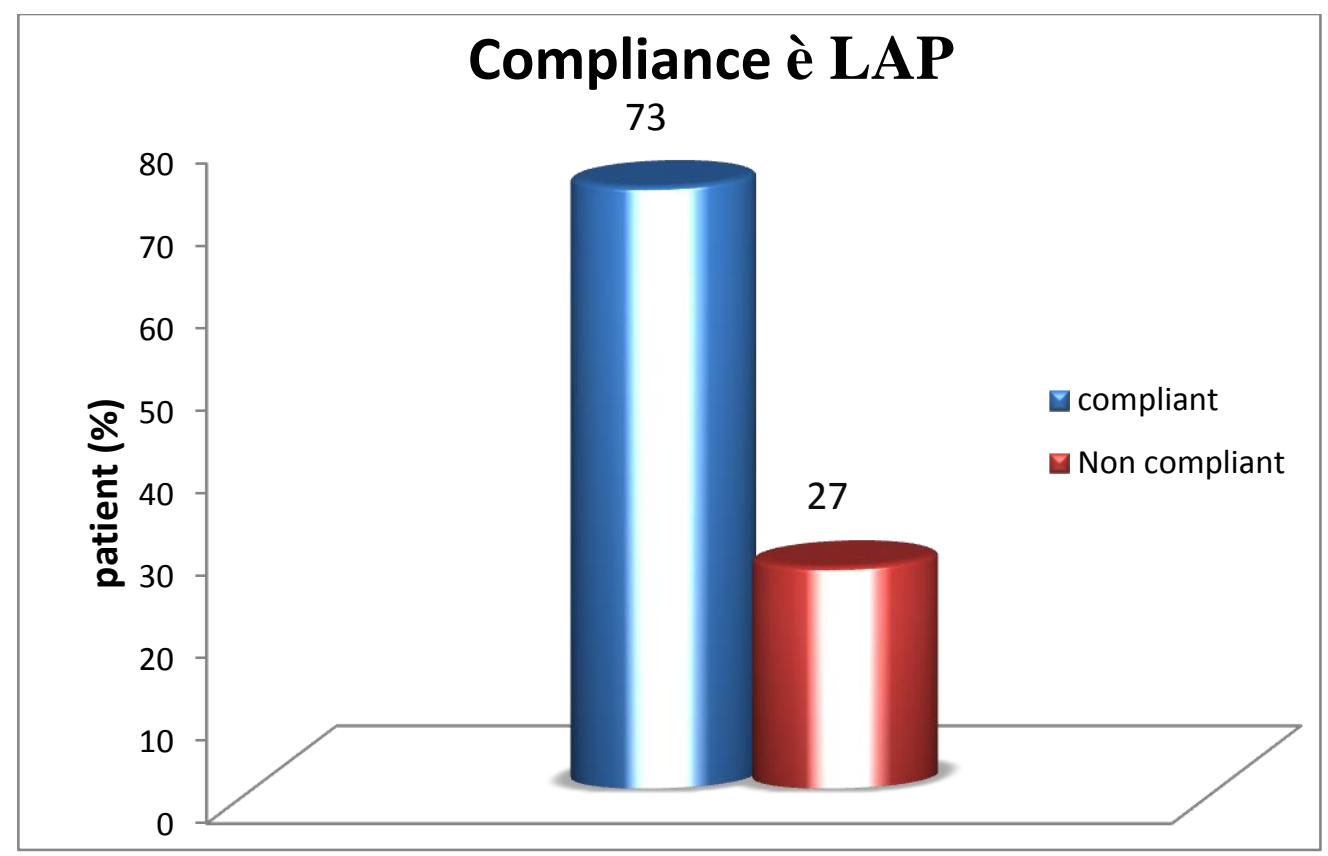

Figure (1): Long acting penicillin compliance

Figure (1) shows that $73 \%$ of the patients who take long acting penicillin were compliant with it, while $27 \%$ were non-compliant with it.

\section{Discussion}

The female patients were commoner than male patients; this is in accord with the known fact on RHD that there is no sex difference in its occurrence ${ }^{(4)}$.

In developing countries, overcrowding, poverty, poor nutrition, poor hygiene, and far distance to health care are common and contribute to rapid spread and increased virulence of streptococcal pharyngitis. With poor access to health care, streptococcal pharyngitis is less likely to be diagnosed and treated, precluding effective primary prevention of rheumatic fever. In addition, cases of RF are more likely to be unnoticed, so secondary prophylaxis is not implemented and recurrence of RF is common ${ }^{(8)}$.

Socioeconomic and environmental factors play important role in the severity of RHD. Factors such as overcrowding, lack of resources for providing quality health-care, inadequate expertise of health-care providers, and a low level of awareness of the disease in the community can all impact the spread of the disease in populations ${ }^{(9)}$.

$\mathrm{X}$-ray was done for nearly all patients in our study at time of admission. If echocardiography is not available, diagnosis of valvular disease must depend on careful clinical examination supported by an electrocardiogram and chest X-ray, but still echocardiography is the modality of choice in diagnosis and management of rheumatic heart disease ${ }^{(10)}$.

Regarding ECG, it was done for most of our patients in this study to detect if the chambers of the heart have enlarged or if there is an abnormal heart rhythm and if there is damage to the heart from heart attack. It was observed that left atrial enlargement was the commonest finding, which occur in cases with mild MS, mild MR, followed by normal X-ray which occur in cases with mild AS, mild AR, then followed by left ventricular enlargement, which occur in cases with mod-severe MR, AR, AS, and TR. Some of multivalvular lesions showed biventricular enlargement. Right ventricular enlargement was noticed in cases with modsevere PS, PR, and MS. Only one case showed abnormal rhythm, prolonged PR interval noticed in some of cases who came with activity as a minor criterion of rheumatic fever. Electrocardiogram is an accurate method for diagnosis of carditis which show structure of the 
heart, blood flow and if there is damage to the valves $^{(11)}$.

However, M-mode, two-dimensional (2D), Doppler and color flow Doppler echocardiography are sensitive method. M-mode echocardiography provides parameters for detecting ventricular function, while 2D echocardiography provides a real-time image for anatomical structure. Two-dimensional EchoDoppler and color flow Doppler echocardiography are the most sensitive for determining abnormal blood flow and valvular regurgitation. The $\mathrm{M}$ and $2 \mathrm{D}$ modes can give accurate measurements of dimensions and thicknesses of the heart chambers ${ }^{(11)}$.

Left atrial enlargement and atrial fibrillation are the common finding in patients with mitral regurge followed by left ventricular enlargement and then right ventricular enlargement. Patients with mitral stenosis left atrial enlargement is the commonest finding and atrial fibrillation is also common ${ }^{(\mathbf{1 2})}$.

Echocardiography is very important tool in the diagnosis of RHD. The technique includes transthoracic, transesophageal, threedimensional and even four-dimensional echocardiography have also been developed to diagnose rheumatic carditis and to assess valvular lesion ${ }^{(\mathbf{1 3})}$.

Some of children with chronic RHD don't take LAP regularly due to painful nature of benzathine penicillin $\mathrm{G}$ injection, development of abscesses at site of injection, missing or forgetting dose, lack of money, absence from market and this can be limited by providing card for each patient, regular follow up visits ${ }^{(\mathbf{1 4})}$.

Penicillin prophylaxis against incidence of rheumatic fever continues to be the main method of secondary prophylaxis in developing countries. In patients with known hypersensitivity to BPG, oral intake of erythromycin should be used. Penicillin V and sulfadiazine were used in non-compliant patients $^{(14)}$.

\section{Limitations of the study}

1- Small sample size of our study due to short duration of the study (six months). investigations.

\section{Conclusions}

Left atrial hypertrophy is the commonest finding detected by ECG. There is increased in left ventricular end diastolic diameter nd left atrium by echocardiography. Ejection fraction and fraction shortening are within normal range. Left atrial hypertrophy is the most common finding in chest X-ray. Mitral valve is the commonest valve affected followed by aortic valve. Pulmonary valve is the least valve affected. Patients' compliant with long acting penicillin are more than non-compliant patients.

\section{Recommendation}

Use of echocardiography as a screening measure for early detection of subtle cases of RHD is recommended. Application of control programs with special emphasis on the regular use of secondary prophylaxis, control of valve overload, regular follow up and regular visits for every patient with chronic RHD, provide card for every patient to avoid missing doses of LAP, and availability of the drug in the market are recommended.

\section{References}

1. Kumar V, Abbas M, Fausto N, Aster J (2009): Robbins and Cotran Pathologic Basis of Disease, Professional edition, $8^{\text {th }}$ edition.

2. Marijon E, Ou P, Celermajer DS, Ferreira B, Mocumbi D (2007): Prevalence of rheumatic heart disease detected by echocardiographic screening. New Engl J Med., 357(5):470-476.

3. Marijon E, Mirabel M, Celermajer DS, Jouven X (2012): Rheumatic heart disease. Lancet, 379(9819): 953-64.

4. Carapetis JR, Steer AC, Mulholland EK, Weber M (2005): The global burden of group A streptococcal diseases. Lancet Infect Dis., 5:685694.

5. Weinstein L, Brusch JL (2010): Infective endocarditis. Oxford University Press, UK.

6. Otto CM, Bonow RO (2007): Valvular heart disease. In: Braunwalds Heart Disease: A Textbook of Cardiovascular Medicine, Libby P, Bonow RO, Mann DL, Zipes DP (Eds.), $8^{\text {th }}$ ed. Philadelphia, PA: WB Saunders.

7. Klug D, Lacroix D, Savoye C et al. (1997): Systemic infection related to endocarditis on 
pacemaker leads- Clinical presentation and management. Circulation, 95(8): 2098-2107.

8. Henningham A, Gillen CM, Walker MJ (2013): Group A streptococcal vaccine candidates: potential for the development of a human vaccine. Curr Top Microbiol Immunol., 368: 207-242.

9. Beaton A, Okello E, Mondo C, Lwabi P, McCarter $R$ et al. (2012): Echocardiography screening for rheumatic heart disease in Ugandan school children. Circulation, 125: 3127-32.

10. Maganti K, Rigolin VH, Sarano ME, Bonow R (2010): Mayo clinic proceedings, 85(5): 483-500.

11. Schoen FJ et al. (2015): The health. In: Robbins and Cotran Pathologic Basis of Disease, $9^{\text {th }}$ ed. Philadelphia, Pa: Saunders Elsevier.
12. Levine RA, Schwammenthal E (2005): Ischemic mitral regurgitation on the threshold of a solution: from paradoxes to unifying concepts. Circulation, 112: 745-752.

13. Minich LL, Tani LY, Veasy LG (2013): Role of echocardiography in the diagnosis and follow-up, evaluation of rheumatic carditis. Available at: https://www.ncbi.nlm.nihi $>$ articles. Page: 221-226.

14. RHD Australia (ARF\RHD Writing Groups), National Heart Foundation of Australia, Cardiac Society of Australia and New Zealand (2012): Australian guideline for prevention and diagnosis. Available at: https://www.rhdaustralia $>$ arf-rhd 